Introduction: Carcinosarcoma (CS) is a tumor with components: epithelial (carcinomatous) and mesenchymal (sarcomatous), developing in the mechanism of epithelial-mesenchymal transition. It is known that the p53 defect is a frequent finding in a carcinosarcoma in different anatomical locations, additionally, in a subgroup of uterine CS MMR defect plays a role in the pathogenesis. The aim of this paper was to investigate the frequency of MMR and p53 aberrations in extrauterine CS.

Material and methods: Twenty eight extrauterine CS from the lung $(n=8)$, breast $(n=6)$, head and neck $(n=5)$, ovary $(n=3)$, urinary bladder $(n=3)$, adrenal gland $(n=1)$, skin $(n=1)$, and stomach $(n=1)$ were stained for hMLH1, PMS2, hMSH2, hMSH6 and p53. The pattern of expression was evaluated separately in carcinomatous and sarcomatous component. Results: Immunostainings for hMLH1, PMS2, hMSH2 and hMSH6 were positive in all tumors. p53 defect was observed in 19 out of 28 samples $(67.85 \%)$. In all cases except one (96.42\%) there was a concordance between sarcomatoid and carcinomatous components.

Conclusions: MMR deficiency does not seem to play a role in the pathogenesis of extrauterine CS. p53 aberrant expression is frequent and almost always consistent in carcinomatous and sarcomatous component.

Key words: carcinosarcoma, p53, MMR.

Contemp Oncol (Pozn) 2020; 24 (1): 1-4 DOI: https://doi.org/10.5114/wo.2020.94718

\section{Immunohistochemical evaluation of mismatch repair proteins and p53 expression in extrauterine carcinosarcoma/sarcomatoid carcinoma}

\author{
Michał Kunc ${ }^{1}$, Anna Gabrych ${ }^{2}$, Bartłomiej Rękawiecki ${ }^{3}$, Adam Gorczyński $^{1}$, \\ Johannes Haybaeck ${ }^{4,5}$, Wojciech Biernat ${ }^{1}$, Piotr Czapiewski ${ }^{1,6,7}$
${ }^{1}$ Department of Pathomorphology, Medical University of Gdansk, Gdansk, Poland ${ }^{2}$ Department of Paediatrics, Haematology and Oncology, Medical University of Gdansk, Gdansk, Poland
${ }^{3}$ Department of Pulmonology, Medical University of Gdansk, Gdansk, Poland Medical University of Graz, Austria
${ }^{5}$ Department of Pathology, Neuropathology and Molecular Pathology, Medical University of Innsbruck, Austria
${ }^{6}$ Department of Pathology, Medical Faculty, Otto-von-Guericke University Magdeburg, Germany
${ }^{7}$ Department of Pathology, Klinikum Dessau, Dessau, Germany \\ ${ }^{4}$ Diagnostic and Research Center for Molecular BioMedicine, Institute of Pathology,
}

\section{Introduction}

Carcinosarcomas (CS) are rare tumors which consist of two malignant components, namely epithelial (carcinomatous) and mesenchymal (sarcomatous). These neoplasms have been observed in various locations among which the most frequent is the uterus, where it is also known as mixed malignant Müllerian tumor (MMMT). Irrespective of the location these tumors show poor prognosis. The ambivalent morphologic presentation of CS raises questions about its origin. To date there have been proposed three main hypotheses aiming to explain the origin of this tumor: 1) the collision theory: carcinoma and sarcoma are two independent neoplasms which arise in the same location and at the same time accidentally together; 2) the combination theory: both components originate from a single stem cell which undergoes divergent differentiation; 3) the conversion theory: the mesenchymal component is derived from an epithelial one. Comparative genetic analyses performed on various CS revealed large overlaps of chromosomal aberrations in both tumor components [1, 2], which speaks in favor of the 2 and 3 hypothesis.

Epithelial-mesenchymal transition (EMT) is a process of losing the epithelial phenotype and acquiring increased migratory potential. Under physiological conditions EMT is involved in the formation of the body plan, regular differentiation of many tissues and tissue repair. Under pathological conditions EMT occurs in many carcinomas and is associated with increased aggressiveness, metastatic potential and chemoresistance. It is generally believed that occurrence of the sarcomatous component of CS is a result of complete EMT [3-6]. However, molecular pathways involved in the process of EMT in CS are not clearly understood and might differ in anatomical locations. For example in pulmonary CS EMT is probably initiated by an upregulation of c-Jun and a consecutive overexpression of Vimentin and Fascin [7], whereas in uterine CS the Wht signaling pathway is deregulated and Akt/ beta-catenin pathway activates Slug inhibiting E-cadherin expression [8]. 
Table 1. Summary of p53 and MMR alterations in current cohort of various carcinosarcoma

\begin{tabular}{|c|c|c|c|c|c|c|c|}
\hline No. & Organ & Age & Sex & $\begin{array}{l}\text { P53 } \\
\text { IHC }\end{array}$ & $\begin{array}{l}\text { MMR } \\
\text { IHC }\end{array}$ & Epithelial component & Mesenchymal component \\
\hline 1 & Skin & 70 & Male & $\mathrm{N}$ & $N$ & SCC & $\begin{array}{c}\text { Chondrosarcoma + } \\
\text { osteosarcoma }\end{array}$ \\
\hline 2 & Ovary & 64 & Female & $A L$ & $\mathrm{~N}$ & Serous carcinoma & Undifferentiated spindle cells \\
\hline 3 & Ovary & 67 & Female & $A D$ & $\mathrm{~N}$ & Serous carcinoma & Undifferentiated spindle cells \\
\hline 4 & Ovary & 55 & Female & $A D$ & $\mathrm{~N}$ & Serous carcinoma & Undifferentiated spindle cells \\
\hline 5 & Adrenal gland & 72 & Male & $\mathrm{N}$ & $\mathrm{N}$ & Undifferentiated carcinoma & Undifferentiated spindle cells \\
\hline 6 & Urinary bladder & 67 & Female & $\mathrm{N}$ & $\mathrm{N}$ & Urothelial carcinoma & Undifferentiated spindle cells \\
\hline 7 & Urinary bladder & 67 & Female & $\mathrm{N}$ & $\mathrm{N}$ & Urothelial carcinoma & $\begin{array}{l}\text { Spindle cells } \\
\text { with myxoid stroma }\end{array}$ \\
\hline 8 & Urinary bladder & 61 & Male & $A L$ & $\mathrm{~N}$ & Urothelial carcinoma & Undifferentiated spindle cells \\
\hline 9 & Lung & 75 & Male & $A L$ & $\mathrm{~N}$ & SCC & Undifferentiated spindle cells \\
\hline 10 & Lung & 62 & Male & $\mathrm{N}$ & $\mathrm{N}$ & $\begin{array}{l}\text { Large cell neuroendocrine } \\
\text { carcinoma }\end{array}$ & Angiosarcoma \\
\hline 11 & Lung & 65 & Male & $\mathrm{AL}$ & $\mathrm{N}$ & SCC + adenocarcinoma & Chondroid differentiation \\
\hline 12 & Lung & 74 & Male & $A D$ & $\mathrm{~N}$ & SCC & Fibrosarcoma \\
\hline 13 & Lung & 68 & Male & $\mathrm{N}$ & $\mathrm{N}$ & $\begin{array}{l}\text { Adenocarcinoma + large cell } \\
\text { neuroendocrine carcinoma }\end{array}$ & $\begin{array}{l}\text { Undifferentiated spindle cells + } \\
\text { myofibroblastic }\end{array}$ \\
\hline 14 & Lung & 59 & Male & $A D$ & N & SCC & Undifferentiated spindle cells \\
\hline 15 & Lung & 69 & Male & $\mathrm{N}$ & N & SCC & Undifferentiated spindle cells \\
\hline 16 & Lung & 71 & Male & $A D$ & $\mathrm{~N}$ & Adenocarcinoma & Undifferentiated spindle cells \\
\hline 17 & Esophagus & 55 & Male & $\mathrm{N}$ & $\mathrm{N}$ & SCC & Undifferentiated spindle cells \\
\hline 18 & Esophagus & 64 & Male & $\mathrm{AL}$ & N & Anaplastic carcinoma & Undifferentiated spindle cells \\
\hline 19 & $\begin{array}{l}\text { Submandibular } \\
\text { gland }\end{array}$ & 91 & Male & $A D$ & $\mathrm{~N}$ & SCC & Pleomorphic mesenchymal cells \\
\hline 20 & Head and neck & 66 & Male & $\mathrm{N}$ & $\mathrm{N}$ & SCC & Chondroid differentiation \\
\hline 21 & Maxila & 36 & Male & $A D$ & $\mathrm{~N}$ & SCC & Undifferentiated spindle cells \\
\hline 22 & Breast & 79 & Female & $\mathrm{AL}$ & $\mathrm{N}$ & Invasive ductal carcinoma, NOS & Undifferentiated spindle cells \\
\hline 23 & Breast & 37 & Female & $A D$ & $\mathrm{~N}$ & SCC & Osteosarcoma \\
\hline 24 & Breast & 69 & Female & $A L$ in $C$ & $\mathrm{~N}$ & Invasive ductal carcinoma, NOS & Undifferentiated spindle cells \\
\hline 25 & Breast & 60 & Female & $A D$ & $\mathrm{~N}$ & Invasive ductal carcinoma, NOS & Undifferentiated spindle cells \\
\hline 26 & Breast & 69 & Female & $A D$ & $\mathrm{~N}$ & Invasive ductal carcinoma, NOS & Undifferentiated spindle cells \\
\hline 27 & Breast & 64 & Female & $A D$ & $\mathrm{~N}$ & Invasive ductal carcinoma, NOS & $\begin{array}{l}\text { Spindle cells with myxoid } \\
\text { stroma + large cell component }\end{array}$ \\
\hline 28 & Stomach & 60 & Male & $A D$ & N & $\begin{array}{l}\text { Adenocarcinoma } \\
\text { with neuroendocrine differentiation }\end{array}$ & $\begin{array}{c}\text { Chondroid differentiation + } \\
\text { leiomyosarcoma }\end{array}$ \\
\hline
\end{tabular}

IHC - immunohistochemistry, $A D$ - abnormal diffuse, $A L$ - abnormal loss, $N$-normal, C - carcinoma

Among all anatomical locations the molecular landscape and pathogenesis are best explored in uterine carcinosarcoma. It is well known that TP53 mutations are essential for CS pathogenesis as the vast majority of CS show concordant overexpression of p53 in the carcinomatous and sarcomatous component [9-11]. Two recent studies have demonstrated an aberrant p53 staining pattern and defective mismatch repair protein (MMR) status in a subgroup of uterine carcinosarcomas $[12,13]$. In one of them p53 aberrant IHC pattern and MMR status were mutually exclusive [13]. However, there are no data about MMR status in extrauterine CS. The aim of this study was the immunohistochemical analysis of p53 and MMR status in a cohort of extrauterine CS.

\section{Material and methods}

Cases of CS recorded at the University Clinical Centre in Gdansk from 2007 to 2015 were retrieved from the archive. Reviews of hematoxylin-eosin stained slides of each case were newly performed by two independent, board certified pathologists (PC, WB) in order to verify the diagnoses. Eventually, 28 formalin-fixed and paraffin embedded tissue blocks were analysed in our study, including tissues from lung $(n=8)$, breast $(n=6)$, head and neck $(n=5)$, ovary $(n=3)$, urinary bladder $(n=3)$, adrenal gland $(n=1)$, skin $(n=1)$, and stomach $(n=1)$ tumors.

The process of IHC and its evaluation has been described in a previous study [13]. Briefly, tumor samples were stained with antibodies against hMLH1 (Clone ES05), 
PMS2 (Clone EP51), hMSH2 (Clone FE 11), hMSH6 (Clone EP49), and p53 (Clone DO-7), all ready to use (DAKO, Denmark). Staining was performed on a Dako autostainer according to the manufacturer's instructions. The slides of all specimens were microscopically evaluated by two experienced pathologists (PC, WB). In the case of MMR proteins, nuclear staining was considered positive, and lack of nuclear staining as negative (a sign of defective MMR). We considered a strong/diffuse (> 75\% of tumour cell nuclei) and a completely negative staining as p53 defect indicative of its mutation, (missense and nonsense, respectively), whereas a patchy/scattered pattern was regarded as a marker of normal p53 function. All statistical analyses were performed using the Statistica 12 (Statsoft). Concordance between sarcomatoid and carcinomatous components were evaluated with Fisher's exact test and kappa test. Other categorical variables were compared by Fisher's exact test.

\section{Results}

Immunohistochemical staining patterns of each tumor along with basic demographic data are shown in Table 1. 28 patients, 16 males and 12 females, were included in the study. Median age at diagnosis was 66.5 (range 36 to 91, average 64.85). Immunostainings for hMLH1, PMS2, hMSH2 and hMSH6 were positive in all tumors.

We detected p53 defects in 19 out of 28 samples $(67,85 \%)$. In almost all cases $(96,42 \%)$ there was a concordance between sarcomatoid and carcinomatous components. In the breast cancer cases the p53 defect was usually reflected by its hyperexpression, while in lung by its complete absence. The patient's characteristics are provided in Table 1.

\section{Discussion}

So far the disturbances in the MMR expression status and/or MSI status was known only in CS of the uterus [1219], with the frequency between 3\% [18] up to 41\% [17]. Two large recent multicentre analyses showed $4 \%$ of deficient MMR expression [20, 21].

In two studies, p53 IHC aberration [18] and TP53 mutation [19] coexisted while in our previous study we observed MLH1 IHC loss due to $h M L H 1$ promotor hypermethylation being mutually exclusive with an aberrant p53 staining pattern and TP53 mutation [13].

MMR deficiency has not been described in extrauterine CS so far and our study has failed to showed it either. In a group of Lynch Syndrome patients with sarcomas there was one CS, however, it was located inside the uterus as well [22]. Our study included tumors of various sites. It has been postulated that CS/sarcomatoid carcinoma in a specific organ is similar either to ordinary carcinoma in this location rather than to CS in another anatomical location [6].

Only in sebaceous neoplasms of the skin there is a frequent loss of MMR, especially MSH2 [23], however, the sarcomatous transformation of these tumors is unknown. MMR-deficiency is infrequent in the lung, breast (around $2 \%$ ) [24], head and neck (around 7\%) [25], ovarian (around 4\%) [26], urinary bladder (around 2\%) [27], stomach (around 6\%) [28] and adrenocortical carcinoma (around 3\%) [29] so the lack of MMR deficiency in our small groups of patients might reflect its frequency in carcinomas.

MMR deficiency is used as a predictive biomarker for the therapeutic efficiency of immunotherapy in solid neoplasms. Our cohort is small, but our results show that MMR probably cannot be used as a predictive marker in CS and other tests should be utilized. The frequent aberrations in the expression of p53 and the almost concordance between the epithelial and mesenchymal component are in line with previous reports [30-34].

\section{Conclusions}

We have observed a high frequency of aberrant p53 IHC expression in CS and their high concordance between the carcinomatous and sarcomatous components. MMR-deficiency was not observed in our group of 28 CS of variable anatomical locations so it does not seem to plays any significant role in its pathogenesis, contrary to the uterine carcinosarcoma, at least what we can state based on our limited sample size.

\section{Acknowledgements}

MK, AG, WB and PC were supported by a grant number ST-95 from the Medical University of Gdansk.

The authors declare no conflict of interest.

\section{References}

1. Vékony H, Leemans CR, Ylstra B, Meijer GA, van der Waal I, Bloemena E. Salivary gland carcinosarcoma: oligonucleotide array $\mathrm{CGH}$ reveals similar genomic profiles in epithelial and mesenchymal components. Oral Oncol 2009; 45: 259-265.

2. Torenbeek R, Hermsen MA, Meijer GA, Baak JP, Meijer CJ. Analysis by comparative genomic hybridization of epithelial and spindle cell components in sarcomatoid carcinoma and carcinosarcoma: histogenetic aspects. J Pathol 1999; 189: 338-343.

3. Cuevas IC, Sahoo SS, Kumar A, et al. Fbxw7 is a driver of uterine carcinosarcoma by promoting epithelial-mesenchymal transition. Proc Natl Acad Sci 2019: 116: 25880-25890.

4. Franceschi T, Durieux E, Morel AP, et al. Role of epithelial-mesenchymal transition factors in the histogenesis of uterine carcinomas. Virchows Arch 2019; 475: 85-94.

5. Harada H, Hosoda K, Moriya H, et al. Carcinosarcoma of the esophagus: A report of 6 cases associated with zinc finger $E$-box-binding homeobox 1 expression. Oncol Lett 2019; 17: 578-586.

6. Pang A, Carbini M, Moreira AL, Maki RG. Carcinosarcomas and related cancers: Tumors caught in the act of epithelial-mesenchymal transition. J Clin Oncol 2018; 36: 210-216.

7. Blaukovitsch M, Halbwedl I, Kothmaier H, Gogg-Kammerer M, Popper $\mathrm{HH}$. Sarcomatoid carcinomas of the lung - are these histogenetically heterogeneous tumors? Virchows Arch 2006; 449: 455-461.

8. Saegusa M, Hashimura M, Kuwata T, Okayasu I. Requirement of the Akt/beta-catenin pathway for uterine carcinosarcoma genesis, modulating E-cadherin expression through the transactivation of slug. Am J Pathol 2009; 174: 2107-2115.

9. Armstrong AB, Wang M, Eble JN, et al. TP53 mutational analysis supports monoclonal origin of biphasic sarcomatoid urothelial carcinoma (carcinosarcoma) of the urinary bladder. Mod Pathol 2009; 22: 113-118.

10. Amatya VJ, Takeshima Y, Kaneko M, Inai K. Esophageal carcinosarcoma with basaloid squamous carcinoma and rhabdomyosarcoma components with TP53 mutation. Pathol Int 2004; 54: 803-809. 
11. Keeling L, Taraporewalla D, Perunovic B, Smith JHF. Uterine carcinosarcoma with p53-positive intraepithelial component. Histopathology 2011; 59: 1277-1278.

12. Saijo M, Nakamura K, Ida N, et al. Histologic Appearance and Im munohistochemistry of DNA Mismatch Repair Protein and p53 in Endometrial Carcinosarcoma: Impact on Prognosis and Insights into Tumorigenesis. Am J Surg Pathol 2019; 43: 1493-1500.

13. Kunc M, Gabrych A, Rekawiecki B, Gorczynski A, Franke S, Haybaeck J, Biernat W, Czapiewski P. MLH1 promoter hypermethylation in uterine carcinosarcoma rarely coexists with TP53 mutation. Contemp Oncol (Pozn) 2019; 23: 202-207.

14. Taylor NP, Gibb RK, Powell MA, Mutch DG, Huettner PC, Goodfellow PJ. Defective DNA mismatch repair and XRCC2 mutation in uterine carcinosarcomas. Gynecol Oncol 2006; 100: 107-110.

15. Taylor NP, Zighelboim I, Huettner PC, et al. DNA mismatch repair and TP53 defects are early events in uterine carcinosarcoma tumorigenesis. Mod Pathol 2006; 19: 1333-1338.

16. Amant F, Dorfling CM, Dreyer L, Vergote I, Lindeque BG, Van Rensburg EJ. Microsatellite instability in uterine sarcomas. Int J Gynecol Cancer 2001; 11: 218-223.

17. de Jong RA, Nijman HW, Wijbrandi TF, Reyners AK, Boezen HM, Hollema $\mathrm{H}$. Molecular markers and clinical behavior of uterine carcinosarcomas: focus on the epithelial tumor component. Mod Pathol 2011; 24: 1368-1379.

18. McConechy MK, Hoang LN, Chui MH, et al. In-depth molecular profiling of the biphasic components of uterine carcinosarcomas. J Pathol Clin Res 2015; 1: 173-185.

19. Jones S, Stransky N, McCord CL, et al. Genomic analyses of gynaecologic carcinosarcomas reveal frequent mutations in chromatin remodelling genes. Nat Commun 2014; 5: 5006.

20. Crane E, Naumann W, Tait D, Higgins R, Herzog T, Brown J. Molecular variations in uterine carcinosarcomas identify therapeutic opportunities. Int J Gynecol Cancer 30: 480-484.

21. Jenkins TM, Hanley KZ, Schwartz LE, Cantrell LA, Stoler MH, Mills AM. Mismatch Repair Deficiency in Uterine Carcinosarcoma: A Multi-institution Retrospective Review. Am J Surg Pathol 2020. doi: 10.1097/PAS.0000000000001434 [Epub ahead of print].

22. Nilbert M, Therkildsen C, Nissen A, Akkerman M, Bernstein I. Sarcomas associated with hereditary nonpolyposis colorectal cancer: Broad anatomical and morphological spectrum. Fam Cancer 2009; 8: 209-213

23. Walsh MD, Jayasekara H, Huang A, Winship IM, Buchanan DD. Clinico-pathological predictors of mismatch repair deficiency in sebaceous neoplasia: A large case series from a single Australian private pathology service. Australas J Dermatol 2019; 60: 126-133.

24. Cheng AS, Leung SCY, Gao D, Burugu S, Anurag M, Ellis MJ, Nielsen TO. Mismatch repair protein loss in breast cancer: clinicopathological associations in a large British Columbia cohort. Breast Cancer Res Treat 2020; 179: 3-10.

25. Vasan K, Satgunaseelan L, Anand S, et al. Tumour mismatch repair protein loss is associated with advanced stage in oral cavity squamous cell carcinoma. Pathology 2019; 51: 688-695.

26. Yamashita H, Nakayama K, Ishikawa M, et al. Relationship be tween microsatellite instability, immune cells infiltration, and expression of immune checkpoint molecules in ovarian carcinoma: Immunotherapeutic strategies for the future. Int J Mol Sci 2019; 20: 5129 .

27. Giedl J, Schneckenpointner R, Filbeck T, et al. Low frequency of HNPCC-Associated Microsatellite instability and aberrant MMR protein expression in early-onset bladder cancer. Am J Clin Pathol 2014; 142: 634-639.

28. Smyth EC, Wotherspoon A, Peckitt $C$, et al. Mismatch repair deficiency, microsatellite instability, and survival: An exploratory analysis of the Medical Research Council Adjuvant Gastric Infusional Chemotherapy (MAGIC) trial. JAMA Oncol 2017; 3: 1197-1203.

29. Raymond VM, Everett JN, Furtado LV, et al. Adrenocortical carcinoma is a lynch syndrome-associated cancer. J Clin Oncol 2013; 31: 3012-3018.
30. Tsuyama S, Saito T, Akazawa Y, et al. Molecular and clinicopathological analyses of esophageal carcinosarcoma with special reference to morphological change. Virchows Arch 2019; 475: 415-424.

31. Kwak H Bin, Park J, Kim HU, Nam KH, Yun SK. Cutaneous carcinosarcoma: A clinicopathologic and immunohistochemical analysis of 11 Korean cases. J Korean Med Sci 2019; 34: e5.

32. Schrock AB, Li SD, Frampton GM, et al. Pulmonary Sarcomatoid Carcinomas Commonly Harbor Either Potentially Targetable Genomic Alterations or High Tumor Mutational Burden as Observed by Comprehensive Genomic Profiling. J Thorac Oncol 2017; 12 : 932-942.

33. Papathomas TG, Duregon E, Korpershoek E, et al. Sarcomatoid adrenocortical carcinoma: a comprehensive pathological, immunohistochemical, and targeted next-generation sequencing analysis. Hum Pathol 2016; 58: 113-122.

34. Armstrong AB, Wang M, Eble JN, et al. TP53 mutational analysis supports monoclonal origin of biphasic sarcomatoid urothelia carcinoma (carcinosarcoma) of the urinary bladder. Mod Pathol 2009; 22: 113-118.

\section{Address for correspondence}

Piotr Czapiewski, MD

Department of Pathology

Medical Faculty

Otto-von-Guericke University Magdeburg

Leipzigerstr. 44, Haus 28

D-39120 Magdeburg

e-mail: czapiewskipiotr@gumed.edu.pl

Submitted: 30.01 .2020

Accepted: 14.03.2020 